\title{
"I Am...": Caitlyn Jenner, Jazz Jennings and the cultural politics of transgender celebrity
}

\author{
Michael Lovelock \\ University of East Anglia
}

Post-print manuscript accepted for publication in Feminist Media Studies. Doi: Forthcoming

The research for this article was funded by a Doctoral Studentship grant from the Arts and Humanities Research Council.

\begin{abstract}
In the twenty-first century, the visibility of transgender celebrities appears greater than ever. Whilst scholarly work has analysed, and continues to analyse, representations of trans celebrities, this research has largely approached these figures as significant because they make transgender visible, rather than the more specific fact that they are celebrities. This article interrogates the role of discourses and tropes of celebrity itself in enabling particular incarnations of trans subjectivity to become intelligible within popular culture. Focusing upon the examples of Caitlyn Jenner and Jazz Jennings, two of the most widely-circulated trans celebrities in the contemporary moment, I argue that the tropes of authenticity, self-reflexivity, self-revelation and manufacture central to celebrity culture, have functioned as core discursive frameworks through which Jenner and Jennings' transgender identities have been rationalised within the popular media. In becoming legible as transgender through celebrity, I argue that Jenner and Jennings' media narratives have worked to confer recognisability to a highly limited model of transgender life, fraught with exclusions around race and gender normativity.
\end{abstract}

Keywords: transgender, celebrity, reality television, Caitlyn Jenner, Jazz Jennings 


\section{Introduction}

In 1952, the world welcomed its first transgender celebrity: a former American GI named Christine Jorgensen, who had travelled to Denmark to undergo one of the first widely-reported cases of gender confirmation surgery. Jorgenson's GI to "blonde beauty" narrative captivated the international press, whose reporting of the Jorgenson case worked to "make transsexual a household word" (Stryker, 2000). Since this time, transgender and celebrity have been intimately intertwined, with transgender celebrities circulating as core textual fabrics upon which transgender identity has become legible as a recognisable subject position within popular culture. In the second decade of the twenty-first century, transgender celebrities have attained intensified visibility as part of what one commentator has labelled a "meteoric rise of transgender people in mainstream media" (Villarreal, 2015), emblematised by figures such as Caitlyn Jenner, Jazz Jennings, Janet Mock and Laverne Cox.

Transgender representations in popular media have long been a focus of scholarly critique. Broadly, this work has interrogated how far the visibility of transgender people in popular culture works to solidify normative gender regimes, or opens up alternative ways of conceiving the relationship between gender and the self, beyond the limits of an essentialised male/female binary (e.g. Halberstam, 2005). In comparison to depictions in fictional media, however, analysis of transgender celebrities has been limited to a small number of studies of individual trans figures (e.g. McIntyre, 2011; Sender, 2014; Morse, 2016). Whilst this work has productively mapped some of the discourses and tropes which have structured the visibility of transgender celebrities across the twentieth and into the twenty-first centuries, implicitly, existing literature has located the significance of trans celebrities as objects of transgender visibility simply in the fact that they make transgender visible within popular culture, rather than the more specific fact 
that they are celebrities. Existing work has analysed the ways in which transgender is represented in and through celebrities, but the specific role of discourses and conventions of celebrity itself within this process are yet to be subject to sustained investigation.

This article therefore interrogates the role that discourses of celebrity, and the tropes and conventions of celebrity mediation more broadly, have played in shaping the ways in which transgender, as a (relatively) coherent and recognizable subject position, has become intelligible within contemporary popular culture. As case studies, I focus upon two of the most widelycirculated embodiments of transgender identity in the contemporary moment: Caitlyn Jenner and Jazz Jennings. Jenner came out as transgender in 2015, after a decades-long career in the media spotlight as the Olympic athlete turned reality star Bruce Jenner. Jennings' visibility is more

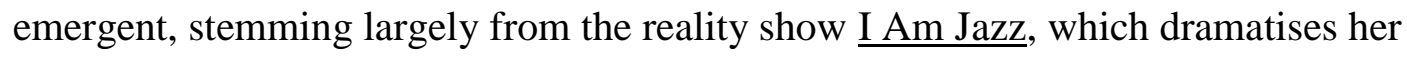
interconnected family life and gender transition process. Jennings is much younger than Jenner:

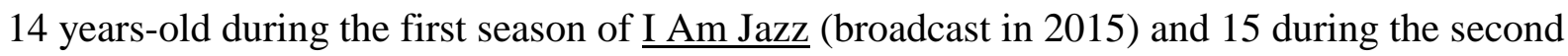
(2016).

This article explores how, in the mediation of these two figures, discourses of celebrity have worked as central epistemological frames through which their transgender subjectivities have been rationalised and made legible within normative frameworks of knowledge. The current burgeoning of transgender celebrities within the mainstream media makes this a timely intervention. The fact that Jennings and Jenner have articulated their trans identities through highly convergent scripts of being "trapped in the wrong body," points to an urgent need to explore the "conditions of possibility" (Hennessey, 2000) which have enabled and delimited transgender subjectivity to attain mainstream cultural coherence through this particular, narrow epistemological norm. I argue that discourses and tropes of celebrity have been instrumental in 
'writing' the meanings of transgender personhood onto the highly visible bodies of Jenner and Jennings. This textual process, moreover, literalises how far the "wrong body" paradigm has become consolidated as the normative understanding of transgender identity in the contemporary moment because this discourse makes sense in the context of broader cultural ideals of authenticity, self-revelation and the power of mediation, which are bound to, and emblematised in, the representational spaces of celebrity culture.

Furthermore, this article seeks to critically appraise the popular demarcation of Jenner's and Jennings' celebrities as bearing progressive, pedagogical and transformative potential. I argue that, in becoming visible through the framework of mainstream celebrity - a representational system which is, by its very nature, shot through with grids of exclusion, power and privilege Jenner's and Jennings' transgender celebrity texts have worked to augment the parameters of normative personhood to encompass a narrow model of transgender subjectivity. This vision of transgender life is easily reconcilable with the commercial tropes of celebrity media and, under the aegis of social transformation, has worked to reaffirm highly normative understandings of gender, race and self-identity, and the relations of power which structure, and are structured by, these norms.

\section{Transgender and Celebrity}

Before Christine Jorgenson, the concept of transsexuality was largely non-existent within mainstream public discourse. Susan Stryker (2000) has argued that faced with a public for whom the concept of transsexuality was meaningless, press articles which sought to report the Jorgensen case strategically drew upon series of established Cold War ideals in order to render Jorgenson's transgender identity meaningful for the American populace. In newspapers and 
magazines, Jorgenson was discussed as an exemplar of the power of modern science and technology to do what had been traditionally considered the province of "nature" (in this case, the artificial construction of the human female body), an idea which already possessed cultural currency in relation to the atomic bomb.

Whilst, unlike Jorgenson, contemporary transgender celebrities such as Caitlyn Jenner and Jazz Jennings are anteceded by over sixty years of trans visibility in American popular culture, as Rosemary Hennessey (2000: 146) has claimed, representations of transgender people in mainstream cultural texts continue to be shaped by "historical conditions of possibility by which the visible becomes seeable." The epistemological basis of transgender subjectivity — that the gender culturally codified by an individual's corporeality might have no ontological bearing upon the "truth" of their identity — poses a challenge to some of the most fundamental, historically-ingrained perceptions of femaleness and maleness as tied to specific bodily properties (Butler, 2004). Therefore, as exemplified by the press's treatment of Jorgenson in the 1950s, mainstream media representations of transgender people have historically employed, and continue to employ, various discursive strategies which render transgender identities coherent and, crucially, consumable, within normative frameworks of knowledge. In pop-cultural texts, transgender emerges into mainstream legibility at the intersection of a range established, culturally-contingent norms, discourses and ideals (which may not be directly "about" gender), which fuse together to produce a particular vision of transgender which has coherency within the historical juncture in which it circulates. As such, media representations do not "reflect," "distort" or bring visibility to a form of identity which already exists, a priori, outside the parameters of the text, but actively construct transgender as a meaningful form of identity within the popular cultural imaginary. 
This is not to argue that transgender doesn't "really" exist, nor to reduce the lived experience of being transgender to a case of identifying with discourses and representations. The phenomenology of living as a transgender individual in the 'real' world in which cultural texts circulate is inevitably multifaceted and complex, so that, to quote Julia Serano (2007: kindle location 215), no representation can "encapsulate all of the intricacies and nuances of the trans [...] experience." Indeed, the ways in which transgender people experience their own identities is not my focus here. Rather, this article seeks to interrogate the crucial role of media discourse, and discourses of celebrity in particular, in enabling transgender to take form as a recognisable identity in mass-market media texts aimed primarily at cisgender-assumed consumers.

Of course, the cisgender/transgender binary is itself a discursive construct. The idea that a small number of individuals (transgender people) have a dysphoric relationship with their gender, but most people don't, is a cultural fiction. As a legacy of feminist and queer theory has argued, gender is a cultural construct, and few people can claim to have never felt at least some form of affective dissonance with the norms and expectations attached to the gender with which they identify (Enke, 2012). ${ }^{\mathrm{i}}$ Yet, the term "cisgender" has limited mobility in popular culture, where, like whiteness and heterosexuality, identifying (problematically or not) with one's birth-assigned gender is construed as a part of a "normal" subjectivity. As such, through their claims to universality and mass appeal, mainstream media texts speak by default to a consumer who is coded as cisgender. Indeed, in media, the hierarchical, majority/minority cis/trans binary has traditionally been reproduced by representations that construct transgender identity as pathological, deceptive and/or ridiculous (Garber, 1992; Serano, 2007). In many of these representations, the transgender person's self-identified gender was positioned as fake or artificial, grounding their "real" identity in their birth-assigned sex (Serano, 2007). 
In the twenty-first century, however, what has been termed the "wrong body discourse" has come to predominate as the normative narrative of transgender subjectivity throughout popular culture (Author, 2016). The wrong body discourse (re)locates the "truth" of gender not in the materiality of the body, but in the more intangible regions of the psyche or the self. Within this dialectic, transgender subjectivity is characterised by the feeling of being born/trapped in the "wrong body." The transgender person feels like a woman inside, but this authentic gendered self is trapped within a mismatched, male-coded corporeality (or vice versa). Any bodily transformations undertaken by the transgender person are thus configured not as changing anything about the self in any fundamental way, but as working to bring the body into alignment with an already-present, "authentic" gendered core. In their mediations, Jenner and Jennings have both recurrently mobilised the wrong body script to articulate their transgender identities. As Jennings has stated, "People think [being transgender] is a choice. It's not at all. It's something you're born with and you realize that you're trapped in the wrong body. It's not like one day you're like, "I want to be transgender!"” (quoted in Ruiz, 2015).

The shifting contours of trans visibility in popular culture emphasise how far normative epistemologies of transgender identity are inextricable from their cultural contexts. It is important to acknowledge that the wrong body script is also the received understanding of transgender identity in the medical and legal domains in the USA and elsewhere and, as such, the sedimentation of this discourse within the popular media is in part informed by these medicolegal contexts. Like the majority of trans subjects, celebrities such as Jennings and Jenner will have had to articulate their senses of self through the wrong body narrative in order to attain medical recognition as transgender and access hormonal or surgical bodily interventions (Butler, 2004). ${ }^{\text {ii }}$ At the same time, however, pop-cultural iterations of the wrong body discourse cannot 
be reduced to a reproduction of medico-legal constructs, and are produced primarily through the tropes, conventions and commercial logics of particular media forms themselves. Elsewhere I have argued that the consecration of the wrong body script within popular epistemologies has been enabled, in part, by a media culture in which working on the body is privileged as the route to realising or articulating the authentic self for all contemporary subjects, cisgender or trans (Author, 2016). Here I want to argue that in Jenner's and Jennings' highly visible celebrity images, the wrong body trope is discursively reproduced through the lens of ideals of selfhood and authenticity bound to the concept of celebrity itself. As such, these celebrities, as celebrities, have been inextricably implicated in the consolidation of the wrong body script as the normative understanding of trans subjectivity in the contemporary moment, in cisgender-targeted media at least. The entangled discourses of celebrity, authenticity and manufacture attached to Jenner's and Jennings' textual representations have functioned as some of the core "conditions of possibility" (Hennessey, 2000) which have shaped the ways in which transgender has become legible within the popular imagination.

\section{Accessing the authentic transgender celebrity self}

The concept of the authentic self has long been central to the commercial logic and cultural work of stardom and celebrity. Discussing the Hollywood movie star Joan Crawford, Richard Dyer (1986: 2) argued, "The whole media construction of stars encourages us to think in terms of 'really' - what is Crawford really like?" Writing in the context of film stardom, Dyer noted that many of the texts which orbited around a star's filmic output claimed to reveal or expose the "real" or "authentic" person behind the cinematic image. Central to this claim was the representation of various "behind-the-scenes" moments, where authenticity was coded "by the use of markers that indicate lack of control, lack of premeditation and privacy" (1991: 141). 
Contemporary celebrity culture remains structured upon the apparent revelation or exposure of celebrities' purportedly authentic selves, with different media outlets competing to offer the most "real" representation of a particular star (Meyers, 2009).

As a cultural phenomenon, celebrity is thus engaged in the work of producing and delineating the idea of the authentic self as a common-sense understanding of self-identity. As mediated through stardom and celebrity, the concept of the authentic self maintains that each individual possesses "an irreducible core of being [...] that is supposed to consist of certain peculiar, unique qualities that remain constant and give sense to a person's actions and reactions" (Dyer, 1986: 7-8). In Western thought, this model of selfhood dates back to Enlightenment philosophy (Taylor, 1991), but became particularly pronounced in the late twentieth and early twenty-first centuries due to the perceived breakdown of traditional, collective anchors of self-identity in the modern world. The meaning of who we are is now popularly perceived to reside in an ontological essence of being rather than in external forces and factors (Rose, 1996), with gender normatively construed as an integral facet of the authentic self; an internal force which permeates individuals' actions, thoughts and feelings (Butler, 2009).

The wrong body discourse of transgender identity clearly aligns with this broader concept of selfhood, positing the transgender person's intuited gender as the essence of their authentic self. In the context of Jenner and Jennings' celebrity images, their authenticity as celebrities has been repeatedly located within their female identities. For instance, Jenner's Vanity Fair interview/photo-shoot through which she introduced her female identity to the public seemingly invited readers/viewers behind-the-scenes, to witness the becoming public of the apparently "real" female self she had been concealing beneath her former, male persona. This shoot transposed the on-screen/off-screen dichotomy of traditional stardom (as conceptualised by 
Dyer) onto Jenner's pre- and post-tradition identities (Bruce and Caitlyn). The photoshoot drew upon the kind of behind-the-scenes aesthetic discussed by Dyer (1991), as the frame through which Jenner's transgender identity was rendered coherent within normative understandings of self-identity. These images are each set in Jenner's private home, high in the hills of Malibu. In the first, Jenner looks out of her patio doors across a vista of sea and sky. A tripod-mounted pair of binoculars in the centre of the frame connote a private, secretive and isolated world, removed from Jenner's public life, and to which readers were finally being granted access. Another image purports to show Jenner relaxing alone in her domestic bathroom, lounging in a chair, head thrown back and eyes closed as if caught unaware. An unfinished glass of wine, half-drunk bottles of water, discarded towels, wigs, hair products and cosmetics litter the surfaces and the floor, signifying an environment unprepared for mediation, and seemingly exposing the ordinarily hidden labour behind the celebrity image. The photographer, Annie Leibowitz, camera flashing as she shoots the seemingly oblivious Jenner, can be glimpsed framing the doorway, reflected in one of the many mirrors which line the bathroom walls. Across the different photographs, extravagant dresses on a stylist's portable rail or discarded on furniture, items of photographic equipment and members of the production crew holding lights and screens are repeatedly visible within the frame.

These images thus centralise the construction of Caitlyn on both a textual and corporeal level. Yet, these semiotics of manufacture are mobilised to bolster the text's claims to authenticity. The conception of transgender bodies naturalised under the wrong body script — constructed and manufactured to express an authentic, internal gendered core - is rationalised within the imagery of the photo-shoot through a visual rhetoric of self-reflexivity which has come to pervade contemporary celebrity culture. As discussed by Rebecca Leach (2001) in relation to 
popular music stars, purporting to expose the means of constructing and mediating a star's public persona, works to ratify the self which undergoes, and is positioned to pre-exist, this mediation as authentic. In this representational frame, part of the labour of producing the star text is visually incorporated into the product itself, a textual strategy which takes into account the apparent difficulty of locating the authentic or "real" in mass-mediated societies, as theorised by postmodern philosophers such as Jean Baudrillard (1983). Celebrity culture has sought to mitigate the ontological anxiety the postmodern era is perceived to have induced, by stressing that beneath the layers of mediation and manufacture which comprise a celebrity's public image, an essential and true self exists and can be unearthed.

In the Vanity Fair photographs, the visual signifiers of self-reflexive access to the authentic celebrity self do additional cultural work, writing the meanings of transgender subjectivity onto Jenner's celebrity body. The internal/external dynamics of the wrong body trope of transgender identity, where the internal self is configured as the location of the real, are mapped metonymically onto the dichotomies of offstage and onstage, private and public, and manufacture and truth which structure the search for the real in celebrity culture. The authentic self which consumers are incited to access through these texts is located in Jenner's newlyrevealed female self, and her identity as a transgender woman is thus made legible through her position as a celebrity.

Within this semiotic and discursive process, Jenner's celebrity also works to 'fix' the meanings of transgender identity in a way that speaks to highly normative notions of gendered selfhood. Sandy Stone (1992: 164) has described the transgender body as a "contested site of cultural inscription," upon which competing conceptions of the relationship between gender and the self vie for cultural legitimacy. Narratives of transgender life as a process of bringing forth an 
"embodied "natural truth"” mobilise the transgender subject as, "a meaning machine for the production of ideal" modes of gender, subjectivity and self-narration. Configured through the wrong body script, the transgender lifecycle becomes exemplary of the neoliberal mandate to realise one's 'authentic' self in order to attain happiness and fulfilment, howsoever defined.

Before proceeding, it is important to emphasise that transgender people do not bear a unique burden to challenge or deconstruct the gender binary (Serano, 2007). Yet, discussing the domain of cultural representations, Stone (1992), Stryker (2006) and other writers across Queer, Feminist and Transgender Studies have maintained that the visibility of transgender people can, in certain contexts, enact a "productive disruption" (Stone, 1992: 165) in relation to binary models of gender. These writers have argued that the manufactured nature of the trans person's corporeality, even as it claims to make tangible a true and essential self, also makes intelligible within the cultural field the possibility that gender has no ontological reality, as it is forged through the "seams and sutures" of discourse and performance (Stryker, 1994).

I would argue, however, that Jenner's textual construction as a celebrity works to shut down the ability for representations of Jenner's transgender identity to enact these kinds of epistemological disruptions. As Katherine Sender (2014) has noted, for transgender identities, mainstream media offers a highly limiting frame of visibility, bringing gender mobility into legibility through readily consumable narratives which do not unsettle traditional understandings of gender and

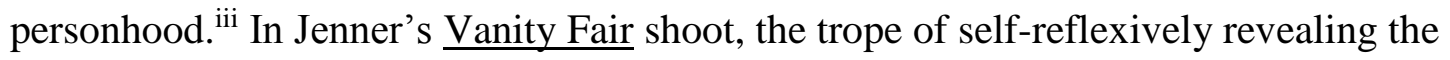
"authentic" celebrity self, well established within the commercial spaces of celebrity culture, operates as a technology of 'cultural inscription' in Stone's terms (1992: 164), narrating Jenner's transition through established understandings of gender as an innate and ontological inner core. This discursive framing enables Jennings' transgender identity to attain coherence and 
consumability for cisgender-assumed viewers, discursively framing her transitional narrative as the making public of an authentic selfhood, in ways that correspond to the commercial grammars of authenticity and self-revelation which structure celebrity culture.

\section{Authenticity, celebrity and the docusoap}

This textual process is also evident in both Jenner's and Jennings' reality TV docusoaps, which offer particularly vivid iterations of the self-reflexive trend in celebrity culture. Merging "raw" documentary aesthetics with soap opera-like characterisations and narrative structures, contemporary docusoaps are highly self-conscious of their own statuses as constructed texts. The docusoap does not attempt to obscure the fact that much of what it represents has been at least partially structured and orchestrated to produce a TV-friendly narrative. At the same time, the form makes a claim to the real in the selves and emotions of the people it represents, which are positioned as having been brought forth into public consumability through the mediated text (Deery, 2015). As a review of I Am Jazz stated, the programme "is full of obvious setups [...] But there's something endearing about the Jennings's awkwardly staged family outings [...] The effort they put into playing themselves makes them oddly more relatable" (Shapiro, 2015).

The logic of the docusoap therefore posits an explicitly manufactured and constructed text as the bearer of ontological truths of subjectivity. Whilst the striking similarly between the titles of

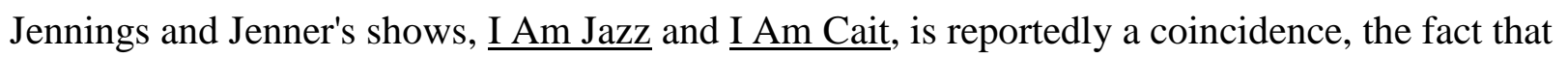
both programmes employ a statement of ontological naming — 'I Am' — as their titles, suggests that mediation through the docusoap form bears the specific potential to somehow confirm, 
validate or authenticate their claimed female identities as who these transgender celebrities "really are."

Like Jenner's Vanity Fair photo-shoot, the rhetoric of self-affirmation evident in the titles of these shows (which, as I explore in relation to Jennings, is further played out throughout the series'), frames Jenner's and Jennings' transgender within celebrity culture's broader claim to offer 'authentic' celebrity selves for public consumption, in an era of increasing cynicism around the status of the 'real' in contemporary social life (as discussed previously). Moreover, the staked authenticity which structures these shows is further compounded by broader cultural perceptions of reality TV as a space of self-authorship and self-narration, particularly in the context of non-

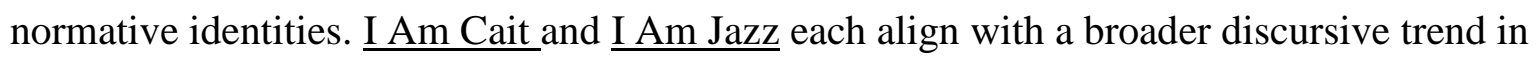
reality programming's treatment of marginalised populations, in which reality formats have long purported to enable sexual or gender minority subjects to speak 'authentically' on their own behalves, rather than be spoken for or represented through heteronormative or cissexist optics (Lovelock, 2015).

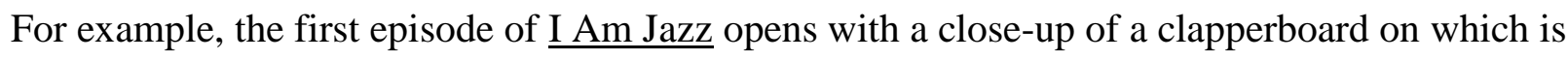
written a scrawl of production details. An off-screen voice calls 'Okay Jazz, we're ready for you,' as Jennings emerges, weaving her way past a clutter of filming equipment. She sits down on a large, cushioned couch in the family's domestic living room, as a member of the television crew approaches, adjusts Jennings' hair and attaches her microphone. The scene cuts to a shot of the filming crew in which a close-up of the seated Jennings is visible on their camera-mounted monitors, reversing back to a mid-shot of Jennings, framed by a crew member who says, "Jazz interview, take one, mark..." as he snaps the clapperboard shut. A disembodied voice asks, "How would you describe yourself?" to which Jennings replies: 
I'm a teenage girl. I'm also a soccer player, I'm an artist, I'd like to think I'm funny, I like hanging out with my friends... I'm also transgender, and I'm proud of that. But you know, in the end, all these things come together and really just make me Jazz. So, I am Jazz.

As Jennings lists the various facets which make up her sense of self, the sequence cuts back and forth between close-ups of Jennings, shots of the monitors on which she is visible to the crew, and longer shots where Jennings, in the background, is framed by pieces of technical equipment in the foreground of the fame. This juxtaposition of the intimacy of the confessional close-up with images which foreground the labour of producing the reality TV text posit a relationship between Jennings' self-affirming statement and the practices of mediation through which it is captured and circulated. Much like Jenner's Vanity Fair cover, the authentic self which viewers are incited to access through this self-reflexive text is positioned within Jennings' female identity, whilst the location of her transgender identity within this framework reproduces the very idea of an authentic transgender self.

In addition, this sequence brings into alignment two technologies of mediated authenticity: the reality TV docusoap and the transgender body. This is also the case in the opening of the first episode of Season One of I Am Cait, where Jenner, her face stripped of makeup, but visibly swollen from recent facial 'feminisation' surgeries, speaks directly into a grainy, shaking camera held in her hand. The epistemological claim of the docusoap: the internal authenticity of participants is brought into public view through mediation and manufacture, converges strikingly with the normative conception of transgender identity encapsulated in the wrong body discourse. Within the wrong body trope, the transgender body, artificially manipulated and transformed through surgery, hormones and the styling of makeup and hair, is configured as a body which has been manufactured to make tangible an essential, already-present core of the self. So too, the 
reality TV docusoap is construed within the popular imaginary as a manufactured entity which, through its very manufacture, brings into visibility essential truths of self and subjectivity.

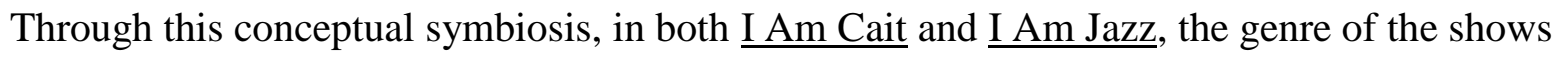
carry the meanings which the programmes ascribe to transgender subjectivity. The discourses of truth and manufacture bound to the docusoap form become the optic through which the wrong body trope is forged into pop-cultural legibility through these texts, and function as the epistemological frame which enables this narrative of transgender life to reproduce its cultural coherence.

\section{Jazz Jennings and the authenticating power of fame}

Whilst the meanings of both Jennings' and Jenner's transgender identities have been structured by the interconnected tropes of authenticity and manufacture bound to the representational apparatus of celebrity culture, there are also core differences between Jenner's and Jenning's celebrity statuses which inflect the representations of their transgender subjectivities. Because of this, I will now approach them individually in order to interrogate how specific facets of their celebrity texts - Jennings' age and Jenner's whiteness - intersect with their constructions as both transgender and as celebrities. In particular, I explore how these intersections position these transgender celebrities as speaking from an apparently 'universal' subject position, in spite of their transgender identities, in ways that seek to secure their circulation within the mainstream economy of celebrity culture.

Unlike the 66 year old Jenner, the teenage Jennings has never had a public, "pre-transition" identity, and has only ever been visible as a subject in transition. As such, Jennings' transgender biography has been intimately intertwined with her concurrent rise into celebrity, as two sides of 
the very-same process. The overarching theme of Jennings' celebrity text has been the extent to which the joint axes of being transgender and being a celebrity have impacted upon her ability to undergo a normative trajectory of (female) teenage life. In I Am Jazz, Jennings' gender transition is dramatized through the optic of her simultaneous movement from middle school to high school, and the transition into late-teenage girlhood which this is perceived to represent. As popular commentators have written, "I Am Jazz is not only about Jennings' journey into puberty [it] is also about a family coming into their own fame," (Villarreal, 2015) whereby "Jazz the spokesperson [for transgender issues] is vying with both Jazz the reality TV star and Jazz the normal teen" (Shapiro, 2015).

The commercial viability of Jennings as a celebrity marketed primarily towards cisgenderassumed consumers is therefore in large part enabled by the continuities between Jennings' intertwined celebrity/transgender narrative and traditional narratives of teenage female stardom. As Melanie Williams (2005: 365) has noted, media interest in girl stars has historically centred upon their 'transformation from girl to woman, and [the] prolonged occupation of the liminal area in between.' In consonance with this trope, I Am Jazz explores how Jennings' inhabitation of a transgender subject position complicates her ability to partake in the (hetero)normative rituals of teenage life, particularly as these relate to her desire to start dating boys. Jennings states that 'being transgender has completely turned boys off from liking me [...] Boys always say 'Hi' to my friends, and hug them, and not me, and I'm just there kinda being ignored"' (S1E2), whilst the narrative synthesis of the first season involves Jennings meeting a boy in the finale episode who is "accepting" of her transgender identity.

On one level, this emphasis upon Jennings' burgeoning (hetero)sexuality can be read as the programme's attempt to render Jennings' transgender identity more "acceptable" for mainstream 
audiences by emphasising her adherence to traditional, heteronormative scripts of teenage life. At the same time, however, these sequences also work to construct Jennings' identity as a site of inherent struggle over meanings, demonstrating how Jennings repeatedly comes up against a social milieu which denies her intuited femaleness and maintains her male-assigned birth sex as

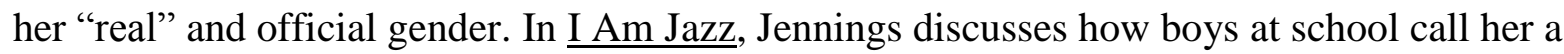
"chick with a dick" behind her back and how in the past she was not permitted to play for the local girls' soccer team. These kinds of prejudices are dramatized in Season One when a passerby calls Jennings a "tranny freak" in the street, and in Season Two where she participates in a debate about the use of her autobiographical children's picture-book in schools, and is called a "sick thing" and a "freak" by audience members.

Jennings' broader inter-textual celebrity image has, however, spoken back to these kinds of transphobic ideals which bind the "truth" of gender to one's physical birth sex, drawing upon discourses of celebrity to cement its claims to authenticity in Jennings' intuited female identity. Jennings' celebrity text has suggested that becoming a celebrity as Jazz has confirmed this female subject position as her "real" identity. This notion is bound especially to Jennings' status as primarily a reality TV star, where celebrity is accrued precisely for performing the purportedly authentic self for public mediation. For example, writing for Dazed magazine, Rowan Blanchard (2016) stated:

I think about what an important icon Jazz Jennings is for teenage girls, as a teenager who has become famous by being herself - which is, arguably, the hardest thing you can do. She also absolutely refuses to apologise for being herself. 
This passage locates Jennings' "iconic" significance not only in her courage to "be herself," but in the fact that she has become famous for doing so, tying the apparent authenticity of Jennings' celebrity persona to discourses of reality television fame as "a process of self-expression, selfrealization and self-validation" (Andrejevic, 2004: 108). Whilst this discourse is particularly pronounced in the context of reality $\mathrm{TV}$, the notion that becoming famous bears the elusive power to endow the self which is mediated "a status traditionally accorded to the realm of the authentic," has a much longer history in Western culture (Tichi, 1991: 137). As Leo Braudy (1997: 6) argued in his study of the history of fame, becoming famous has long been perceived to enable individuals "to be what one really is, one's true, unchanging essence."

Jennings' narrative demonstrates how such popular conceptions of the power of celebrity to validate the self which is mediated as authentic, can take on very particular meanings in the context of different forms of identity. Jennings' inter-textual celebrity image has been replete with imagery and discourses which have constructed her rise to celebrity as a process of authenticating her female self through the power of mass mediation. A 2015 BuzzFeed article, for example, quoted Jennings as responding to a question about "what it's like seeing herself onscreen," with, "I really hope it'll show people that I'm just the average person living my life authentically and embracing the fact that I'm transgender" (Shapiro, 2015). The interview was accompanied by an image of Jennings busting thorough billowing red curtains, as if onto a theatre stage. Towering in a low-angled shot, she is shown gripping the curtains with arms outstretched, head high and eyes straight ahead, signifying confidence and determination. In a later image, Jennings is shot from behind, hands on her hips as she looks out from the stage into the darkened auditorium. The metaphor of the stage clearly signifies Jennings' public visibility, semiotically tying her status as an "empowered" transgender subject — defined in this text 
through her courage to live an authentic life — to her celebrity status. Becoming a celebrity is construed as a process of realizing and affirming her authentic female self in the face of a sociality which has often denied the "truth" of her intuited female identity. In turn, the validating and authenticating powers associated with the phenomenon of fame, work to rationalise and reproduce the concept of transgender identity as an authentic self brought forth from within a mismatched corporeal core, as embodied in the figure of Jennings.

\section{Validation, para-social intimacy and gender normativity}

The rhetoric of "empowerment" and "authenticity" which structure the BuzzFeed image of Jennings also points to the extent to which celebrity status operates as a means of discursively validating this particular model of transgender life as a recognisable and legitimate form of subjectivity. Within their celebrity texts, the mass-media visibility of both Jennings and Jenner has been tied to pedagogical missions to effect heightened public awareness of transgender issues. As Jennings has stated of her own celebrity, "I just really hope it will open up people's minds, and it'll help people be more accepting and tolerating of transgender people in general" (Shapiro, 2015). For Jennings, her apparent pedagogical value as a highly visible embodiment of transgender identity has again been located in her status as a reality TV star. Within this discourse, the emphases upon emotionality, authenticity, intimacy and domesticity which characterise the reality docusoap, where Jennings has become famous by simply "being herself," are endowed with a subjectifying function. These tropes are purported to enable cisgender audiences to experience transgender identity through a framework of transcendental humanity, rather than as a signifier of otherness. For example, in Season One Episode Five of I Am Jazz, 
Jennings is described as putting "a human face on a misunderstood topic." Later in the episode she is approached at a book signing by a young transgender man who tells her, "People like you are paving the way and making [transgender] visible... thank you, just in general, for being you."

Jennings' celebrity thus appears engaged with the ways in which cultural recognition as a human subject is unequally allocated, and how far "gender and sexual norms condition in advance who will count as a subject, and who will not" (Butler, 2009: iv). In its construction of Jennings as the "human face" of transgender identity, the programme appears to speak back to a cultural history in which transgender people have been perceived as "less that fully human," and abjected from normative conceptions of personhood (Stryker, 1994: 238). Throughout modern history, those whose genders do not clearly correspond with a binary logic have been designated within normative cultural imaginaries as "precarious lives," in Judith Butler's (2009) terms, as outside the bounds of what constitutes a recognisable human subject. This discursive allocation of humanity along axes of normative/non-normative gender identities becomes brutally manifest in the disproportionate levels of physical and symbolic violence (such as poverty and unemployment) suffered by transgender populations. As Butler (ibid: ii) states, precarity is "directly linked with gender norms, since we know that those who do not live their genders in intelligible ways are at heightened risk for harassment and violence."

As a celebrity who is produced primarily through reality TV, a "technology of intimacy [...] that functions by drawing viewers close" (Kavka, 2008: 5), Jennings circulates through a semiotic and discursive repertoire which emphasises the apparent affinities between Jennings and the cisgender public who consume her image. This has been interpreted by commentators as overriding the non-normativity of her transgender identity, as a review in The Advocate stated: 


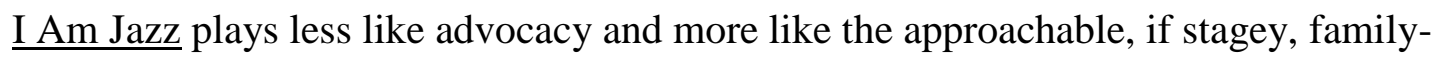
reality hybrids cable has made a staple. Reality shows like these $[\ldots]$ introduce the $[\ldots]$ audience to virtual neighbors many of them don't have in real life (Villarreal, 2015).

In representing Jennings as an "approachable neighbour" to the cisgender viewer, her representations have enacted a partial opening up of the parameters of the "human" subject — an ideological construct traditionally coded as white, heterosexual and cisgender — to encompass the formation of transgender subjectivity which she embodies. Crucially, Jennings' celebrity operates within this process as a technology of recognition in relation to her trans identity. In contemporary society, celebrity is one of the most intense forms of social and cultural validation. As Jo Littler (2004: 10) has stated, celebrity:

Becomes a means of symbolic validation, a way to 'really' exist, to mean something in public and private, to be rich with symbolic as well as material capital. To seek the full glare of celebrity media validation is to strive against the hidden injuries of disempowerment.

In the context of Jennings, the symbolic capital of celebrity, and its perceived ability to "validate" the existence of those who become celebrities, attains a transformative and humanising potential. Jennings' ability to become a celebrity functions, on a representational level, to validate and legitimise transgender people as recognisable human subjects, or those whose identities converge with Jennings' own, at least.

As a celebrity, Jennings has circulated as an "ideal" vision of transgender life, one which is "acceptable" for recognition within the parameters of the human. The purportedly progressive and inclusionary scripts which have structured Jennings' celebrity are therefore shot through 
with grids of exclusion, conferring humanity selectively to a model of transgender identity which does little to challenge or critique the normative grids of knowledge, power and privilege which abjected transgender bodies from the human fold in the first place.

This diffusion of critique is bound to Jennings' status as a celebrity who circulates through texts which are produced by mainstream media corporations and addressed to mass-market audiences. The commercial viability of celebrities is secured, in large part, by the extent to which their representations are able to forge "para-social relationships" with consumers, feelings of emotional intimacy with public figures only ever encountered in mediated form (Barron, 2015). Through their reproduction in formats based upon authenticity, emotional intimacy and 'being yourself,' reality TV celebrities most especially are perceived to straddle cultural dichotomies of the ordinary and the extraordinary. Much of the commercial appeal of reality stars is located in their apparent relate-ability and enduring ordinariness in spite their fame, in ways that seemingly correspond to viewers' own lives, identities and experiences (Barron, 2015). In this way, TLC executives have acknowledged that I Am Jazz was commissioned due to its thematic fit with established docusoaps on the channel, about "ordinary" families facing "extraordinary" circumstances (e.g. Kate Plus 8 and Little People, Big World). As Marjorie Kaplan, the president of TLC, has stated, "What our audience comes for are families that they can identify with, and Jazz's family fits in that universe in a very comfortable way" (quoted in Shapiro, 2015).

The network's apparent need to render Jennings a "comfortable" object of consumption appears to exhibit, on some level, an awareness on their part of the radical potential of trans visibility as conceptualised by writers like Stone (1992) and Stryker (1994). In order to position Jennings as a commercially viable reality TV star, her celebrity image is deeply invested in asserting the apparent normalcy of her female identity, not only in spite of her growing celebrity status, but 
also in spite of the location of this female identity within a mismatched, male-coded corporeality. For instance, Jennings has repeatedly articulated her apparently authentic female self through a series of highly traditional (even stereotypical), essentialist markers of female subjectivity. These include a claimed life-long fascination with 'girlie' clothes and toys, her burgeoning romantic interest in boys, and a seemingly innate maternal instinct, which is represented to emerge in the first season of I Am Jazz when Jennings asks her older sister to be her pregnancy surrogate in the future.

Jennings' celebrity is thus structured upon a 'despite' logic in relation to her transgender identity. Her ability to circulate as a viable figure of para-social identification is enabled by her very visible striving to adhere to highly normative scripts of female subjectivity despite being transgender. In Jennings, the symbolic validation of celebrity operates as an index of acceptability for transgender identities in contemporary cultural life, delineating transgender subjectivity as only suitable for mainstream visibility when it is subsumed into normative ideals of gendered behaviour. In becoming visible through Jennings, transgender, paradoxically, becomes somewhat invisible, articulated as a recapitulation of established norms around what it means to inhabit a teenage female subject position, albeit one which is, in this instance, located within a male-coded body.

\section{Caitlyn Jenner and the whiteness of transgender celebrity}

Whilst, as I have argued, Jennings' celebrity image confers recognition to a limited model of transgender subjectivity, as an incredibly wealthy, normatively feminine, white woman, the exclusionary nature of Caitlyn Jenner's transgender celebrity is perhaps even more apparent, and has been widely discussed in popular commentary (e.g. Pilkington, 2015). Much of Jenner's early 
mediations, however, sought to pre-empt this kind of critique by openly acknowledging Jenner's socio-economic and racial privilege. For example, in Season One Episode Two of I Am Cait, one of the cast members remarks critically upon "A system which makes [Jenner's coming out] the one we finally listen to, when we've been ignoring the stories of black and latina transwomen."

Much like Jennings, Jenner's celebrity has been attributed a pedagogical and transformative function, and the stated mission of I Am Cait was to use Jenner's celebrity capital to shed light on issues affecting marginalised transgender populations. At the same time, across her celebrity image, representations of Jenner's privilege also perform the commercial function of appealing to para-social identification between Jenner and her consumers. Anita Brady (2016) has noted that I Am Cait foregrounds Jenner's "education" in how to be an appropriate, politically-aware spokesperson for the transgender community. As such, both Jenner and the viewer are similarly positioned to be "learning" about transgender issues through I Am Cait; the viewer because they are assumed to be cisgender (and mostly white), and Jenner because her celebrity status has shielded her from the realities of life for poor and ethnic minority trans people. Jenner's racial and class position therefore locate her within a highly ambivalent discursive framework. Her vast material wealth is clearly at odds with the experiences of most consumers. At the same time, however, her whiteness is mobilised within her celebrity text as a means of discursively negating the otherness of her transgender subjectivity (and her wealth), constructing her simultaneously as a figure of difference and identification for white, cisgender audiences. The audience are addressed as ignorant in transgender issues and, the series claims, so is Jenner herself due to her status as a white celebrity.

Jenner's celebrity therefore both idealises and universalises her whiteness, which is positioned as simultaneously linking Jenner with viewers, and distancing her from the poor trans people of 
colour she purportedly seeks to help through the show. In mobilising her racial position as a marker of universality between celebrity and consumer, Jenner's celebrity performs the ideological claims of whiteness to "speak for a common humanity" (Dyer, 1997: 2), against which non-white populations emerge as marked "others." At the same time, on a visual level, Jenner's representations have reproduced a historical relationship between stardom and the

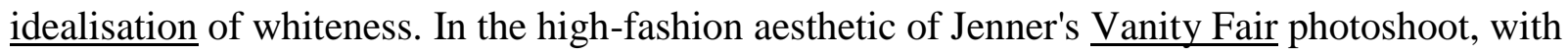
its softly-lit, golden-tinted filtering, Jenner's pale complexion appears to physically glow, a visual style which has extended to Jenner's straight-to-camera confessional sequences in $\underline{\mathrm{I} \text { Am }}$ Cait. This binding of the glamour of celebrity with the visuality of whiteness situates Jenner's transgender body within a representational framework which, as Sean Redmond (2007: 263) has stated of cisgender female film stars, “ontologically privileges and secures this form of whiteness as the highest ideal available to man/woman." Simultaneously, in drawing upon Jenner's whiteness as a marker of para-social commonality, in Jenner's mediations, the very subject position of man/woman becomes inherently coded as white.

Indeed, the world of marginalised transgender people which Jenner sets out to explore in I Am Cait is explicitly racialised as non-white, and is represented metonymically in the show through the figure of Blossom. Blossom is a black, working-class trans woman whom Jenner meets during a visit to the Human Rights Center in San Fransisco, and who claims to have been rejected from nursing school six times due to transphobia. Hearing her story, Jenner decides to intervene and, returning from the meeting, is shown calling the show's producer in front of the camera, telling her:

I want you to take [the footage of Blossom sharing her story at the HRC], I want you to edit it together, and I want you to give it to me. We're gonna get her on the Ellen 
DeGeneres show; I'm gonna call Ellen, and she's gonna go to nursing school, and we're gonna pay for it.

Here, Jenner's status as a celebrity who moves in media and show-business circles becomes the framework for the articulation of a kind of transgender white saviour narrative, in which Jenner employs her visibility, celebrity contacts and material capital to "save" a poor, black transgender woman. Blossom did indeed appear on Ellen in September 2015, where she was presented with a cheque for $\$ 20,000$ and DeGeneres made a public appeal for nursing schools to come forward and offer Blossom a place.

Whilst Jenner/DeGeneres' celebrity philanthropy provided a momentary reprieve for one marginalised poor, black, trans subject, Jenner's construction as speaking, through her whiteness, for a universal, majority white-assumed, cisgender-coded viewer position, constructed Blossom and the poor, black trans people she was mobilised to represent, as racially-marked, desubjectified figures, requiring the intervention of white celebrities to speak for them, and provide conduits to social integration. If whiteness, for Caitlyn Jenner, functions as a signifier of commonality between transgender star and cisgender-assumed, white-assumed viewer, Jenner's broader celebrity text works to reify Blossom's otherness to this norm wrought by the intersections of her queernss and her race. Paradoxically, in claiming to help marginalised transgender populations, on a discursive level, Jenner's celebrity reproduces the cultural-political grids of racial, economic and gendered power which excluded Blossom from the social fold, represented by her repeated rejections from medical school, and thwarted ambitions to be a 'productive citizen' as Jenner herself terms it in the show. As a celebrity, Jenner's media visibility has thus worked to augment the category of universal humanity to include a deeply exclusionary 
model of transgender identity which aligns with prevailing racial codifications of human subjectivity as white subjectivity.

\section{Conclusion}

At a cultural moment in which the visibility of transgender celebrities appears greater than ever, this article has argued that, through these figures, discourses and conventions of celebrity itself have been instrumental in producing and circulating a series of normative epistemologies on what it means to be transgender in the contemporary moment. As the examples of Caitlyn Jenner and Jazz Jennings have shown, in the mediation of transgender celebrities, tropes of authenticity, self-reflexivity, self-revelation and manufacture central to the commercial logic of celebrity culture have functioned as some of the key discursive frameworks through which a "wrong body" narrative of transgender life has attained mainstream cultural coherence and recognisability. Moreover, this discursive process, played out in the celebrity images of trans celebrities, literalises a broader context in which the wrong body paradigm has become consolidated as the normative understanding of transgender subjectivity because this concept makes sense in relation to broader ideals of authenticity, gender and the self which permeate celebrity culture

My analysis of Jenner and Jennings has also demonstrated how celebrity operates as a matrix of exclusion in relation to transgender visibility in mainstream media texts. The celebrity images of transgender stars are shaped by various conditions of visibility, which seek to render trans celebrities safe objects of consumption for cisgender-assumed audiences. This is particularly pronounced in the context of celebrity, and reality TV celebrity especially, where commercial 
longevity is contingent upon the forging of para-social commonality between celebrities and their consumers. In order to secure such para-social relationships, Jennings and Jenner's representations have asserted the sameness between these transgender figures and their audiences, evoking whiteness (coded as a non-raced universality) and adherence to normative gender roles as binding forces which are positioned to override the otherness of their transgender identities to the normative, white, cisgender subject position articulated by mainstream media texts. Whilst, on a representational level at least, this can be seen as augmenting the parameters of recognisable human subjectivity to encompass some forms of transgender life, at the same time, this process of recognition-via-celebrity extends only to a select vision of transgender existence, one which reaffirms the grids of gendered and racial exclusion which pervade the very model of the human.

\section{References}

Andrejevic, Mark. 2004. Reality TV: The Work of Being Watched. Oxford: Rowman and Littlefield.

Barron, Lee. 2015. Celebrity Cultures: An Introduction. London: SAGE.

Baurdillard, Jean. 1983. Simulations. New York: Semiotext(e).

Blanchard, Rown. 2016. "Jazz Jennings and Rowan Blanchard reject the noise." Dazed, Spring. Accessed June 27 2016. http://www.dazeddigital.com/artsandculture/article/29683/1/jazzjennings-rejects-the-noise 
Brady, Anita. 2016. "'Caitlyn Jenner 'likes' Ted Cruz but the feeling may not be mutual": Queer pedagogy and the politics of Caitlyn Jenner." Paper presented at Celebrity Studies Conference, University of Amsterdam.

Braudy, Leo. 1997. The Frenzy of Renown: Fame \& its History. New York: Vintage.

Butler, Judith. 2004. Undoing Gender. London: Routledge.

Butler, Judith. 2009. "Performativity, Precarity and Sexual Politics." AIBR, 4 (3): i-xiii

Deery, June. 2015. Reality TV. Cambridge: Polity.

Dyer, Richard. 1986. Heavenly Bodies: Film Stars and Society. Basingstoke: Macmillan.

Dyer, Richard. 1991. "A Star is Born and the Construction of Authenticity." In Stardom: Industry of Desire, edited by Christine Gledhill. London: Routledge.

Dyer, Richard. 1997. White. London: Routledge.

Enke, A. Finn. 2012. "The Education of Little Cis: Cisgender and the Discipline of Opposing Bodies." In Transfeminist Perspectives: in and beyond Transgender and Gender Studies, edited by Anne Enke, 60-77. Philadelphia: Temple University Press.

Garber, Marjorie. 1992. Vested Interests: Cross-Dressing and Cultural Anxiety. London:

Penguin.

Halberstam, Judith. 2005. In Queer Time and Place. London: New York University Press.

Hennessey, Rosemary. 2000. Profit and Pleasure: Sexual Identities in Late Capitalism. London: Routledge. 
Holmes, Su and Negra, Diane. 2011. In the Limelight and Under the Microscope: Forms and Functions of Female Celebrity. London: Continuum.

Kavka, Misha. 2008. Reality Television, Affect and Intimacy. London: Palgrave.

Leach, Rebecca. 2001. "Vicars of 'Wannabe': Authenticity and the Spice Girls." Popular Music, 20(2): 143-167.

Littler, Jo. 2004. "Making fame ordinary: intimacy, reflexivity and 'keeping it real'," Mediactive, 2: $8-25$.

Lovelock, Michael. 2015. “Acceptance, humanity and emotional excess: The politics of queer suffering in Big Brother UK.” European Journal of Cultural Studies. Doi:

$10.1177 / 1367549415603375$

McIntyre, Joanna. 2011. "He Did It Her Way on TV: Representing an Australian Transsexual Celebrity Onscreen." Gay and Lesbian Issues and Psychology Review, 7(1): 19-32.

Meyers, Erin. 2009. "Can You handle My Truth?”: Authenticity and the Celebrity Star Image." Journal of Popular Culture, 42(5): 890-907

Morse, Nicole. 2016. "A double-take on reality television: Laverne Cox's political and pedagogical gestural humor." Feminist Media Studies. Doi: 10.1080/14680777.2016.1171792 Prosser, Jay. 1998. Second Skins: The Body Narratives of Transsexuality. New York: Columbia University Press. 
Redmond, Sean. 2007. "The Whiteness of Stars: Looking at Kate Winslet's Unruly White Body." In Stardom and Celebrity: A Reader, edited by Su Holmes and Sean Redmond, 263-274. London: SAGE.

Rose, Nikolas. 1996. Inventing Our Selves: Psychology, Power, and Personhood. Cambridge: Cambridge University Press.

Ruiz, Michelle. 2015. "Jazz Jennings: The Transgender Teen and Wannabe Mermaid the Internet Needs." Cosmopolitan, 8 June. http://www.cosmopolitan.com/entertainment/tv/a40068/jazzjennings-internets-most-fascinating/

Sender, Katherine. 2014. 'Transgender, Transmedia, Transnationality: Chaz Bono in Documentary and "Dancing with the Stars".' In Routledge Companion to Media and Gender, edited by Cynthia Carter, Linda Steiner and Lisa McLaughlin, 300-321. New York: Routledge.

Serano, Julia. (2007). Whipping Girl: A Transsexual Woman on the Scapegoating of Femininity. Emeryville: Seal Press.

Shapiro, Amanda. 2015. "Jazz Jennings is Finding her Voice." BuzzFeed, 25 September. Accessed 27 July 2016. https://www.buzzfeed.com/ashapiro009/jazz-jennings-is-finding- hervoice?utm_term=.wvoQPKMXZ\#.ngQ0WgKVr

Stone, Sandy., 1992. The Empire Strikes Back: A Posttranssexual Manifesto. Camera Obscura. 10: $150-176$.

Stryker, Susan. 1994. "My Words to Victor Frankenstein above the Village of Chamounix: Performing Transgender Rage." GLQ, 1(3): 237-254. 
Stryker, Susan., 2000. 'Transsexuality: The postmodern body and/as technology.' In The Cybercultures Reader, D. Bell and B. Kennedy (eds.). London: Routledge.

Taylor, Charles., 1991. The Ethics of Authenticity. London: Harvard University Press.

Tichi, Celia., 1991. Electronic Hearth: Creating an American Television Culture. New York and Oxford: Oxford University Press.

Villarreal, Yezmin. 2015. "I Am Jazz: 14, Transgender, and the star of My Own Doc-series." 29 July. Accessed 27 July 2016. http://www.advocate.com/transgender/2015/07/29/i-am-jazzjennings-14-transgender-and-star-my-own-docu-series

Williams, Melanie. 2005. "'I'm not a lady!": Tiger Bay and transitional girlhood in British cinema on the cusp of the 1960s." Screen, 46(3): 361-72.

' In making this point, I do not wish to conflate transgender and cisgender experience. Various studies have discussed the qualitative differences between the ways in which transgender and cisgender-identifying people experience their identities on a day-to-day basis (see, for example, Enke, 2012).

iI It is also important to acknowledge that many transgender people identify with the idea of being "trapped in the wrong body" for a plethora of reasons which far exceed their encounters with medico-legal scripts and media representations (see Prosser, 1998). 
iii The reproduction of cultural norms is, of course, not unique to transgender celebrities. Much research within Celebrity, Media and Cultural Studies has explored the extent to which the broader field of celebrity culture operates as a disciplinary arena for the re-inscription of hegemonic ideals of gender and femininity (see, for example, Holmes and Negra, 2011). 